\title{
1 New Alternatives in Seafood Restructured Products
}

2 Helena MORENO ${ }^{\mathrm{a}}$, Beatriz HERRANZ ${ }^{\mathrm{a}}$, Miriam PÉREZ-MATEOS ${ }^{\mathrm{a}}$, Isabel

3 SÁNCHEZ-ALONSO ${ }^{b}$ and Antonio J. BORDERÍAS ${ }^{a}$

$4{ }^{a}$ Instituto de Ciencia y Tecnología de Alimentos y Nutrición (ICTAN-CSIC), José

5 Antonio Novais 10, 28040 Madrid, Spain.

6 b Instituto de Estructura de la Materia (IEM-CSIC), Serrano 121, 28006 Madrid, Spain.

7

8 A general overview, focusing on new trends in the different techniques used in

9 restructured seafood product processing has been described in this work. Heat induced

10 gelation has been more widely studied in scientific literature than cold gelation

11 technology. This latter technology includes the use of hydrocolloids (alginates and

12 glucomannan) or enzymes (microbial transglutaminase) for making both raw and

13 cooked restructured products. In restructuration processes, fortification processing with

14 some functional ingredients is studied, giving as a result extra value to the products as

15 well as increasing the variety of new seafood products. The process of alleviating heavy

16 metals and organic pollutants from the raw material used has also been studied in the

17 present paper.

Keywords: restructured seafood, cold gelation, microbial transglutaminase, sodium alginate, glucomannan, dietary fibre, fatty acids, pollutant alleviation.

INTRODUCTION

[Escriba aquí] 
Restructured seafood products are foods made from minced and/or chopped muscle, which are used with or without additional ingredients or additives, to make other products with either a new appearance or texture or both. For some time now, there have been products on the market made from under-valued fish species or byproducts in the form of fish fingers or other shapes, designed basically to attract children. Seafood products are also being elaborated by different restructuration techniques to mimic other more highly-valued products. The main reason for restructuring fish muscle has been due to the limitations on high value seafood product supplies and, therefore, the necessity to make the best use of existing resources. Many of these resources are under-utilized species that would otherwise have commercial problems because of their size, composition, bony structure, unattractive appearance or texture. Additionally, fish by-products (muscle trimmings, sawdust from frozen fish sawing, etc.), from regular processing of more expensive species, can be used as raw material for the elaboration of restructured seafood products (Borderías and PérezMateos, 1996; Ramirez et al., 2011). chopped muscle pieces or mince, most of them, especially the seafood analogues, are elaborated from surimi. This is a stabilized myofibrillar protein paste, obtained after washing and refining the mince, which has good long-term frozen storage stability and excellent gel-forming ability. When fish mince or surimi is used, it is frequently necessary to create different types of structures in order to endow the final product with better textural properties. For that purpose, gelation is induced to develop myotome-like fibres (CSIC, 2006) or other structures. Restructured products can also be very good carriers for functional ingredients, since there are fewer technical restrictions compared 
The aim of this paper is to describe the current technology used in the

elaboration of restructured seafood products, which includes heat-induced gelation, cold gelation adding different ingredients, new possibilities for adding functional ingredients and contaminant alleviation of raw material. As there is a lot of published information about heat-induced gelation in the elaboration of restructured products, this review will only touch on this subject lightly.

\section{HEAT-INDUCED GELATION}

This is the most common procedure used in the industry to process restructured seafood products, from both surimi and minced muscle. Heat gelation involves the gelation of myofibrillar proteins, mostly myosin. It happens after the addition of enough salt permits the myofibrillar proteins to unfold, thereby inducing the exposure of their reactive surfaces, and thus facilitating interactions, so intermolecular bonds are formed. When these kinds of bonds are sufficient in number a three-dimensional network is formed resulting in a gel. Different types of bonds take place to form this network, such as hydrogen bonds, ionic interactions, hydrophobic interactions and covalent bonds (Lanier et al., 2005). It is important to note that hydrophobic interactions and covalent bonds are the interactions responsible for gel thermostability, an important characteristic to be considered for food products that will be cooked.

If after unfolding by salting, the dough is kept at a low temperature $\left(0\right.$ to $\left.50^{\circ} \mathrm{C}\right)$, myofibrillar proteins can form a softer and more deformable gel, named suwari gel; this process is termed setting. This type of gel network is formed as a result of the enzymatically catalysed formation of non-disulphide covalent bonds between the amino acids glutamine and lysine on unfolded proteins under the effect of a calcium dependant transglutaminase, naturally present in fish muscle (Lanier et al., 2005). The temperature 
at which proteins are unfolded and bonded in this process is different depending on the species. So in cold-water fish better results are obtained at temperatures of around $25^{\circ} \mathrm{C}$, whereas suwari gels made with warm-water species show better mechanical properties when incubated at higher temperatures nearer to $40^{\circ} \mathrm{C}$ (Ramírez et al., 2011). An alternative way of developing suwari in fish gels is by protein denaturation induced by high pressure, where gels with a more deformable texture and a shinier colour are obtained. In this case, the hydrophobic bonds play a predominant role (Perez-Mateos et al., 1997). Subsequent heating of suwari gels at $80-90^{\circ} \mathrm{C}$, results in the formation of stronger gels than without low-temperature pre-incubation (Lanier et al., 2005). To get different textures from heat gelation a number of ingredients and additives are used. These additives can act, both by interacting with the proteins or as fillers in the protein network (Park, 2005; Ramírez et al., 2011).

87

\section{COLD GELATION}

In recent decades, there has been an increasing demand for minimally processed products. For this reason, the development of cold gelation technology is becoming an 91 interesting option for elaborating restructured fish products with a raw aspect. Products elaborated by this method are very versatile and can be commercialised in many different ways, such as fresh ready-to-cook fish fillets, small fillet pieces to put into brochettes, carpaccio-like sushi or ready-to eat-dishes, and also in marinated or smoked products (CSIC, 2006; Moreno et al., 2008, 2010a, b). There are many different ways of elaborating restructured products by using cold technology because of the different binding agents available. In cold gelation, protein muscle aggregation is mostly due to the action of different bindings that are able to act at sufficiently low temperatures

99 without inducing changes in the raw aspect of the product (Moreno et al., 2008). 
100 Moreover, by using these binding agents, it is also possible to manufacture added-value

101 products in which final texture will also depend on muscle size and quality,

102 composition, the specific binding agent employed and the treatment applied (Moreno et

103 al., 2009a, 2010a, c).

104 Two of the most widely used binding additives in fish restructuration are

105 alginates (mainly sodium alginate) and microbial transglutaminase (MTGase)., Recently

106 however, new scientific studies have suggested the incorporation of konjac

107 glucomannan in seafood mince in order to make it possible to elaborate structures from

108 non-functional raw material.

109

110 Alginates

111 Alginates are hydrocolloids that play an important role in the structure, stability

112 and functional properties of several processed foods. Alginates are alginic acid salts that

113 are extracted from brown seaweeds (Laminaria sp., Macrocystis sp., etc.) known by the

114 name of Kelp. They are linear polysaccharides composed of $\beta$-D-manuronic acid and $\alpha$ -

115 L-guluronic acid.

116 The use of alginates in food technology (Sodium alginate was approved as E-

117401 by the European Food Safety Authority in 2007) started to become of interest in the

118 1960’s, when they were used to elaborate protective coatings, such as casing substitutes,

119 and for structure/texture modification in fresh and further processed products, initially

120 in meat. It is also considered a GRAS substance by the United States Department of

121 Commerce. Alginate coatings were also reported to increase shelf-life by delaying

122 odour development, dehydration, and off-colour in fresh products such as apples

123 (Nussinovitch, 1998). Furthermore, alginates can be added to minced fish muscles as it 
124 is the alginate molecule network that communicates texture to minced muscle (Pérez-

125 Mateos and Montero, 2000; Lu et al., 2010).

126 In order to form a thermostable network, alginates require the presence of

127 different polyvalent ions. Calcium is the divalent ion most commonly used to elaborate

128 alginate thermostable gels, because its interaction with alginates is superior to that of

129 other polyvalent cations (Rourke et al., 1997; Boles and Shand, 1998). In this process,

130 the solubilized sodium alginate forms thermostable gels capable of binding comminuted

131 or ground fish muscle, producing as a result structures of different textures (Moreno et

132 al., 2008, 2010a). The alginate network interacts with myofibrillar proteins, but these

133 interactions seem to be mainly electrostatic between the anionic groups on the alginate

134 and the positively charged groups on the proteins (Rourke et al., 1997; Montero et al.,

135 2000). The interaction between alginates and proteins is determined by the hydrocolloid

136 concentration and calcium ion sources. In a comparative study of cold gelation of

137 minced fish batters supplemented with different calcium sources and sodium alginate,

138 Moreno et al. (2011) indicated that restructured products could be made firmer with

139 calcium chloride than with the other calcium sources (calcium lactate and caseinate). On

140 the other hand, the proportion of sodium alginate, calcium source, setting time and

141 conditions were the main variables used to achieve different kinds of texture, and

142 needed to be properly analysed in order to optimize the process. According to this

143 study, depending on the texture desired in hake muscle (Merluccius capensis)

144 restructuration, the concentration of calcium chloride was shown to be more effective at

$1450.1 \%$ than at higher concentrations, while sodium alginate was commonly ranged from

$146 \quad 0.05 \%$ to $0.5 \%$ (Moreno et al., 2008, 2011). Moreover, the presence of salt and fat up to

147 levels of $3 \%$ and $5 \%$ respectively did not significantly affect the texture of

148 alginate/muscle systems (Beriain et al., 2011; Moreno et al., 2011). 
150 Transglutaminase

Transglutaminases (TGases, EC 2.3.2.13, glutaminyl-peptide, amine- $\gamma$-glutamyl-

transferase) belong to a class of enzymes which catalyse the acyl transfer reaction between the $\gamma$-carboxamine group of a peptide-bound glutaminyl residue and a primary amino group of various substrates (Motoki and Seguro, 1998). which is widely distributed in plants and animal tissues, and microbial transglutaminase (MTGase). In relation with fish muscle, endogenous transglutaminase (TGase) promotes protein cross-linking in myofibrillar proteins in surimi and seafood mince at temperatures lower than $50^{\circ} \mathrm{C}$.

Microbial transglutaminase is secreted by Streptoverticillium mobaraense or Streptomoces mobaraense (Motoki and Seguro, 1998). It is the principal commercially available purified transglutaminase for food (Ajinomoto Handbook, Activa®). Although, MTGase is considered a GRAS substance by the United State Department of

164 Commerce, the European Food Safety Authority (FSA, 2007) is still studying its use in 165 the food industry. The great advantage of MTGase over endogenous TGase is that MTGase 167 activity is totally independent of $\mathrm{Ca}^{2+}$. MTGase optimum temperature is around $20-50^{\circ} \mathrm{C}$ 168 depending on the specific enzyme preparation (Ajinomoto Handbook, Activa ${ }^{\circledR}$ ) and the 169 substrate, although there is activity at $5^{\circ} \mathrm{C}$ in fish muscle (Moreno et al., 2010a,b). This 170 fact makes MTGase a good option in the preparation of gelled products at low 171 temperature without inducing changes in the raw aspect of the final product (Moreno et 172 al., 2008) and also with raw materials of different qualities and salt content. In this 173 sense, Moreno et al. (2009a) have reported that variations in muscle protein quality (due 
174 to different frozen storage histories) is extremely important when elaborating

175 restructured products by joining pieces of muscle, but not when the purpose is to gel a

176 finely homogenate muscle. Moreover, the $\mathrm{pH}$ of the mince used to elaborate the

177 restructured products should be controlled, especially if the added salt content is

178 particularly low (Moreno et al., 2010c). It is also important to note that MTGase activity

179 is clearly potentiated by adding sodium caseinate at around $1.0 \%$, especially in cold

180 gelation processes. Additionally, the incorporation of soy protein isolate and whey

181 protein improves MTGase activity, though clearly in a less significant way when

182 compared with sodium caseinate (Kuraishi et al., 1997).

183 The combination of transglutaminase and isostatic high pressure, whether or not

184 coupled with the heating process, has been studied by various authors (Ashie and

185 Lanier, 1999; Moreno et al., 2009b) and has led to the conclusion that a setting ranged

186 between $25-40{ }^{\circ} \mathrm{C}$ prior to high pressure treatment is very suitable for the preparation of

187 gels with improved mechanical properties. In this sense, it has been demonstrated that

188 transglutaminase activity, both endogenous and microbial, is not hindered by 100-600

189 MPa; and even remains active during a subsequent setting process (Lee and Park, 2002).

190 However, pressures higher than $200 \mathrm{MPa}$ could induce changes in the raw colour,

191 leading to a cooked appearance; an important point that should be taken into account

192 when considering the final properties of the product (Moreno et al., 2009b).

193

194 Glucomannan

195 When seafood muscles have been previously processed by heating, as is the case 196 of canned tuna, cooked octopus, "sawdust" from fish block sawing, etc., the protein

197 functionality of the by-products is lost to a great extent. This is a problem, if these by198 products are going to be used in seafood restructuration, as the gelation will be weak, 
even though MTGase is used. The same happens if a certain level of fat content is high

200 in the fish muscle that is going to gel (Moreno et al., 2009a; 2010b). To overcome these

201 problems, konjac glucomannan has recently been studied by Herranz et al. (2012a, b) for use as a gelling agent where minced muscle would act as filler (CSIC, 2011).

of Amorphophallus konjac C. Koch. It has been used as a food and food additive in

205 China and Japan for more than 1000 years. It has been recognized as safe (GRAS) since 1994 (Takigami, 2000; Zhang et al., 2005), was authorized as a binder in meat and poultry products by the U.S. Department of Agriculture (USDA) in 1996, and has been approved as E-425 by the European Food Safety Authority (FSA, 2007). Apart from this, KGM provides several health benefits such as lowering blood, cholesterol and sugar levels, as well as promoting intestinal activity, immune function, etc. (Vuksan et al., 1999). In Western countries its consumption has increased recently among obese people owing to its potential as a dietary fibre because of its effective water-absorbing ability (Chua et al., 2010).

KGM consists of a linear backbone of $\beta$-1,4-linked D-mannose and D-glucose and $5-10 \%$ of acetyl substituted residues which are assumed to be responsible for the solubility of KGM in water. The loss of these acetyl groups in an alkaline media, resulting in the formation of a thermostable gel, is the basis of many traditional oriental foods such as noodles, tofu and snacks (Chua et al., 2010; Douglas et al., 2005).

Even so, the use of KGM is not very extended in the seafood industry and few

220 references can be found in scientific literature. Park (1996) observed that the addition of 221 5\% konjac flour to whiting (Merluccius productus) and pollock (Theragra chalcograma) surimi reinforced gel hardness by a factor of 8-10 in both of them. This author also concluded that surimi gels containing konjac flour exhibited an important 
224 ability to maintain consistent shear strain values against repeated freeze/thaw abuse, that

225 konjac flour (up to 2\%) increased gel lightness, and that yellowness intensified as 226 konjac flour was added (up to 5\%). Iglesias-Otero et al. (2010) used an aqueous solution 227 of $\mathrm{KGM}(10 \%)$ in a proportion of $1 \%$ in giant squid (Dosidicus gigas) surimi at 228 different $\mathrm{pH}$ values to improve quality. These authors concluded that at $\mathrm{pH} 10.4$ the 229 surimi gelation showed an increase in strain amplitude and a decrease in the frequency230 dependence of storage $\left(\mathrm{G}^{\prime}\right)$ and loss $\left(\mathrm{G}^{\prime \prime}\right)$ moduli; resulting in an improvement in gel 231 properties. On the other hand, Xiong et al. (2009) showed that 1\% of KGM could work as well as a conventional crioprotectant on myofibrillar proteins from grass carp (Ctenopharyngodon idella) muscle during frozen storage.

Based on the ability of glucomannan to make thermostable gels, Herranz et al. (2012a, c) studied the possibility of KGM acting as a gelling agent in minced fish, forming a network in which the fish muscle particles could act as a filler. This would provide the possibility of using a wide variety of seafood muscles whose completely denaturalized protein, due to previous proccesses, had made it either incapable of gelating or that its gel-forming ability was poor. Hence, a wide range of restructured products after gelating in the form of fibre or myotomes could be elaborated and commercialized as fresh, frozen or cooked products (Borderías et al., 2012). Furthermore, due to the fat binding properties of this gel (unpublished data), the nutritional characteristics of these products could be improved so that functional ingredients such as omega-3 polyunsaturated fatty acids (n-3 PUFAs) from fish oils and conjugated linolenic acid (CLA) from vegetable oils could be included in the network formed by KGM. Additionally, based on the large amount of water (around 86\%) that restructured muscle elaborated with a mixture of KGM and muscle contains, these products could be used in hypocaloric diets. 
Before the application of glucomannan as a gelling agent in the elaboration of restructured seafood products, an exhaustive study on glucomannan gelation was carried out to choose the type and concentration of glucomannan and alkali, as well as the setting time and neutralization conditions of the process (Herranz at al., 2012a; Herranz at al., 2012c). From these studies, it was concluded that the best conditions to solubilize the glucomannan and obtain aqueous glucomannan solutions (AGD) were 30 minutes at $60^{\circ} \mathrm{C}$ in a homogenizer and $5 \%$ of $\mathrm{KOH}$ at $0.6 \mathrm{~N}$ to raise $\mathrm{pH}$ values to $11.8-12.0$, resulting in complete deacetylation. After the alkali was added, a two-step setting was applied to obtain a thermostable gel (first 1 hour at $30^{\circ} \mathrm{C}$ followed by another of 4 hours at $5^{\circ} \mathrm{C}$ ). After that, the gel was placed in a buffer until neutralization. When this gel was heated at $50-70^{\circ} \mathrm{C}$, the gel became even more stable (Herranz et al., 2012b).

Next, a study of fish muscle analogue prototypes elaborated with a solution of glucomannan and non functional muscle was carried out (Herranz et al. 2012c). The solution was made up of aqueous glucomannan dispersions (AGD) at different concentrations (3 and 6\%,v/v) and non-functional mince ("sawdust”) obtained from sawing frozen hake (M. capensis) blocks. The different glucomannan:sawdust ratios were 50:50 and 25:75 w/w and the processing was the same as that for glucomannan gelation alone, reported above. The different determinations carried out (lightness, water binding capacity, puncture test and sensorial analysis) showed that the gel formed by $6 \%$ AGD (w/v) added in a proportion of 25:75 to the non-functional muscle,

269 produced a prototype with textural and flavour characteristics similar to those of fish 270 (hake) muscle (Herranz et al., 2012c). 
In recent years, an increasing interest in the design of functional products has

274 been noted. However, the potential for the development of functional seafood products

275 has not yet been fully exploited (Careche et al., 2011). The fact that during restructured

276 seafood processing, small pieces or mince are reshaped provides an excellent

277 opportunity for including some bioactive ingredients in this fish muscle matrix. Some

278 functional ingredients such as dietary fibres (DFs), phytosterols, carotenoids, natural

279 antioxidants, n-3/n-6 fatty acids and vitamins are widely used in the design of functional

280 foods and new ones are emerging e.g. antioxidant DFs. The present production of

281 functional seafood products is limited compared to other foods, as seafood is mainly

282 used as a source of bioactive components (e.g. fish oils or protein powders) to develop

283 alternative functional foods.

\section{Dietary fibres in fishery products}

286

DFs are regarded as the most widely used functional ingredients in foods, but

287 they have rarely been incorporated in seafood. The addition of DFs to fishery products

288 is of great interest, not only as a means to further complement their healthy

289 characteristics, but also as a means of improving the technological properties of the 290 products such as water binding, gelling, etc. (Borderías et al., 2005). Thus, most of the

291 DFs used in seafood products are soluble (e.g. carrageenan, guar, inulin) and usually 292 selected because of their high water binding, emulsifying, thickening or gel-forming 293 ability (Park, 2005).

294 In the case of insoluble DFs, experience of their use in seafood products is more 295 limited (Borderías et al., 2005). However, nowadays interest in the use of insoluble DFs 296 and other DF sources, mainly from fruits, with a well-balanced soluble:insoluble ratio 297 has increased significantly. Other types of DFs of particular interest in this area are 
antioxidant DFs that are mainly obtained from fruits and seaweeds, which contain both

299 DF (>50\%) and natural constituents with specific antioxidant capacity (Saura-Calixto, 300 1998). The addition of antioxidant DFs to restructured fish products could serve not 301 only to include DF in seafood diets but also delay lipid oxidation of polyunsaturated

302 fatty acids (PUFA), both of which appear in the list of positive compounds for 303 nutritional claims in the EU regulation (EC, 2006; EU, 2010). A Consumer Product Test 304 has also shown that there is an opportunity to develop new seafood products enriched in 305 DFs well-adapted to consumer preferences (Borderías et al., 2008; Careche et al., 306 2008a). This fact can be considered as a new business opportunity for some industries. 307 Therefore, this section reviews the inclusion of these insoluble DFs, both high cellulosic 308 and antioxidant DFs, in restructured seafood products.

\section{Commercial insoluble dietary fibres}

Wheat DF (Vitacel ${ }^{\circledR}$ ) is one of the insoluble DFs (iDFs) most widely-used as a

312 food ingredient. It is composed of $74 \%$ cellulose, $26 \%$ hemicellulose and $<0.5 \%$ lignin,

313 which endows it with highly insoluble properties and fat binding capacity. It is white in

314 colour and neutral in taste and smell. It was previouly stated that in Alaska pollock ( $T$.

315 chalcograma) and giant squid (D. gigas) surimi gels, the inclusion of wheat DF at

316 concentrations of 3 and 6\%, fibre grain sizes 80 and $250 \mu \mathrm{m}$ long, and at constant final

317 moisture conferred an extra whiteness on the products (Sánchez-Alonso et al., 2006,

318 2007d). Moreover, from the point of view of gelation, these gels can be regarded as

319 good quality gels, even though water retention properties and hence mechanical 320 properties and texture were altered. This would be as a consequence of the proportional 321 reduction of protein content in the gel, which may also be associated with the irregular 322 network formed due to the addition of the non-gelling wheat DF compound. The 
323 particle size of the added wheat DF is also relevant, thus it is not necessarily the case

324 that the higher the water holding capacity of the DF the better the formulation. In fact, 325 this can have the effect of dehydrating the protein. This was found to be the case with 326 wheat DF, where two separate moisture compartments can occur in the matrix, 327 indirectly impairing the gel-forming capacity of the muscle protein (Sánchez-González 328 et al., 2009). Furthermore, wheat DF makes softer and more deformable gels and this 329 attenuates the gummy texture which is not well-accepted in Western countries 330 (Sánchez-Alonso et al., 2007d). In minced hake (Merluccius merluccius) and horse mackerel (Trachurus trachurus) fish muscle, Sánchez-Alonso et al. (2007a) studied the incorporation of wheat DF levels of 3 to $6 \%$. In this case, the main technological advantages of including wheat DF in minced fish was its effectiveness in binding water

334 of battered products, thus preventing the coating from breaking and the cooked portions 335 from deforming. Besides this, the restructured products are softer and less cohesive, 336 which may be an advantage for some end products. Sensory analysis suggests that the 337 addition of a 3\% wheat DF concentration is better for minced fish muscle (Sánchez338 Alonso et al., 2007a).

The above-cited authors in association with a company producing restructured 340 fish products, successfully included wheat DF in two commercial products, and a 341 Consumer Product Test was performed with 500 consumers in order to check the 342 sensory acceptability as well as the concept of DF inclusion in seafood products. The 343 results showed that products with information about DF content and its health benefits 344 generated positive expectations in the consumers. Consumers only detected differences 345 in attributes related to texture, thus the optimization step and scaling up was performed 346 successfully, developing a product which could be labelled "high in dietary fibre" 347 (Careche et al., 2007; Dopico et al., 2007; Borderías et al., 2008). 
Another commercial cellulose DF used as an ingredient in restructured seafood

349 products is a cellulose powder (Solka-Floc ${ }^{\circledR}$ ) that effectively reduces the usage level of cryoprotectants, sweetness and the amount of modified starch needed in surimi products, thereby achieving a non-starch texture. This kind of cellulose also prevents gelled products from becoming rubbery and dry during frozen storage by reducing freeze syneresis and improving water binding (Yoon and Lee, 1990). There is also inner

354 pea DF (Swelite ${ }^{\circledR}$ ) on the market that is beneficial in safeguarding the textural properties of hake (M. capensis) and sea bass (Dicentratus labrax) heat-induced gel products (Cardoso et al., 2007, 2011). However, effects can differ between fish species, for instance, this DF did not improve the gel strength of mackerel (Scomber scombrus and S. japonicus) surimi gels but instead increased hardness and other related parameters (Cardoso et al., 2009).

\section{Non-commercial dietary fibres: antioxidant dietary fibres}

Although antioxidant DFs (ADFs) have been non-commercial until now, it is important to consider them in this review because of their beneficial properties. Some of the most interesting ADFs are grape concentrates produced from various white or red grape by-products (skin, seeds or pomace). Grape DF has a high content of total DF (>70\%) and a relatively high content of soluble DF in comparison with total DF. Moreover, the presence of associated polyphenolic compounds ( $>5 \%$ ) endows the DFs with antioxidant properties (Sánchez-Alonso et al., 2007b, 2008b). As a source of

369 antioxidant DF, these ADFs were added to restructured products made from horse mackerel, a semi-fatty fish species very prone to oxidation (Sánchez-Alonso et al.,

371 2007b, c, 2008b; Sánchez-Alonso and Borderías, 2008). Both white and red grape DF

372 added to minced horse mackerel muscle significantly increased its water holding 
capacity. It also reduced thaw drip after frozen storage, and significantly increased the

374 cooking yield due to the reduction in drip loss during heating; cohesiveness and 375 hardness were also reduced. Furthermore, adding 2\% grape DF produced an acceptable product in sensory terms and delayed lipid oxidation in frozen minced muscle stored at $20^{\circ} \mathrm{C}$ for up to 180 days (Sánchez-Alonso et al., 2007b, 2008b; Sánchez-Alonso and Borderías, 2008). On the other hand, Careche et al. (2008b) reported that the inclusion of DF, alone or together with natural antioxidants associated with the DF, led to sensorially acceptable restructured products made of fish muscle that fulfilled the requirement of "source of dietary fibre" and/or "high content of fibre" according to EU regulations (EC, 2006). Antioxidant DFs could also act by delaying PUFA oxidation with the subsequent nutritional and sensory advantages associated with these products. Some consumer studies have been conducted on fish mince (Salmon sp.) with added grape DF (Careche et al, 2008a, b), and one of the consequences arising from the results of these consumer studies was the interest in using alternative sources of ADF, as consumers preferred their seafood products to be supplemented with DFs of marine origin e.g. seaweed concentrates (Careche et al., 2008b). Thus, Díaz-Rubio et al. (2011) studied the nutritional profile of Fucus spp. seaweed ADF and its technological effect on minced horse mackerel (T. trachurus) during frozen storage. This ADF is composed mainly of DF (>60\%) with a relatively high soluble content (16\% of total DF) and more than $5 \%$ of associated phenolic compounds. The study demonstrated that minced fish

394 samples supplemented with fucus ADF (1\% and 2\%) had lower lipid oxidation than 395 those without it, and the total drip after thawing and cooking was reduced during frozen 396 storage. Fish samples with $1 \%$ fucus DF did not differ in flavour from the samples without DF (Díaz-Rubio et al., 2011). 

products. Senthil et al. (2005) reported that up to $10 \%$ of red seaweed, Eucheuma 400 (Kappaphycus alverezii) powder could be added without adversely affecting the appearance, texture and acceptability of fish (Pampus argentius) cutlets. Recently, a range of innovative seafood products enriched with coloured ADFs has been developed 403 from seaweed or grapes, based on a new product idea, similar to the "Swiss roll, that the authors have named "brazo de gitano" (CSIC, 2010). One of these prototypes is made up of a covering of surimi-based gel enriched with wheat DF, stuffed with a mixture of minced fish muscle and freeze-dried seaweed (Ulva rigida) (Sánchez-Alonso et al., 2008a). The seafood prototype contains sufficient DF to be labelled as a "source of DF" (EC, 2006). The foregoing shows that it is possible to make restructured colourful products with an attractive image and sensory acceptability, thereby overcoming the main barriers discouraging the application of some very interesting antioxidant DFs (grapes, seaweeds) (Sánchez-Alonso et al., 2008a).

\section{Fatty acids in seafood restructured products}

414 Lipids are one of the ingredients which can be incorporated into surimi products

415 as a texture modifier, colour enhancer, or processing aid (Park, 2005). In fact, vegetable 416 and animal lipids are often added to surimi products since fish muscle can produce a 417 stable emulsion with them. In this context, food products with added PUFAs $(\omega-3)$ are 418 in increasing demand due to their demonstrated health benefits, confirmed by the 419 appearance of PUFAs in the positive list of compounds for nutritional claims in EU 420 regulations (EU, 2010). Pérez-Mateos et al. (2004) reported little changes in sensory properties and lipid oxidation of fortified surimi seafood (crab analogue) during 2 
423 from different sources (fish oil concentrate, menhaden oil, or purified marine oil).

424 Recently, Pietrowski et al. (2011, 2012) demonstrated that the nutritional value, colour 425 and gelation of Alaska pollock surimi seafood can be enhanced, without altering texture 426 properties, by the addition of $9 \%$ omega-3 PUFA-rich oils (flaxseed, algae, menhaden, 427 krill). Also, cod (Gadus morhua) surimi was fortified with $\omega$-3 fatty acids (500 mg of $428 \omega$-3 fatty acids per serving of surimi $\sim 85$ g) from algal oil with good oxidative stability 429 and gel strength (Park et al., 2004). Cardoso et al. (2010) successfully developed a 430 ready-to-eat minced fish product from hake containing dietary fibre (inner pea DF) and 431 fortified with $\omega$-3 fatty acids (2.9\% deodorized cod liver oil). Another type of functional fatty acid is conjugated linoleic acid (CLA) which 433 refers to a mixture of different isomers of linoleic acid (18:2n-6) commonly found in 434 beef, lamb and dairy products. A commercial CLA oil was added to Alaska pollock 435 surimi gels instead of sunflower oil, at a dosage (3.7 grams of CLA isomers per 100 grams of sample) that has been reported to have beneficial health effects (Whigham, Watras and Schoeller, 2007) without modifying appearance, mechanical properties or water binding capacity (Sánchez-Alonso and Ayo, 2007).

\section{CONTAMINANT ALLEVIATION DURING MINCE PROCESSING}

Although it is well known that fish and shellfish contain high levels of pollutants

442 due to the accumulative process of biomagnification, scarcely any literature has been

443 found about its elimination. The uptake and distribution of pollutants in seafood varies 444 depending on factors such as physiological and environmental conditions, age, size, sex, 445 body weight, etc. (Pourang et al., 2004). Heavy metals are distributed in diverse tissues 446 (muscle, internal organs, fatty tissues, etc.), but in most cases, the highest concentration 447 of heavy metals is found in the hepatopancreas, probably because of its high 
metallothionein content (Pourang et al., 2004; Ren et al., 2008). In this regard, the

449 higher levels of heavy metals in molluscan (Mediterranean mussel, Mytilys 450 gallopronvincialis) than in fish (rainbow trout, Oncorhyncus mykiss) could be due to the 451 fact that mussel metallothioneins are more reactive than fish proteins to metal binding 452 (Vergani et al., 2005). Persistent organic pollutants accumulate mainly in the fatty tissue 453 due to its lipophilic nature. during the washing stage of the pieces of muscle or, even better, once the muscle has been minced owing to the small size of the minced particles.

\section{Chelating washing technique to reduce heavy metal contamination}

Among the main procedures for alleviating heavy metals is the chelating 460 washing technique, where ligands bind to toxic metals from the muscle by forming strong water-soluble complexes that can be eliminated by washing. The efficiency of the process can be affected, on the one hand, by the chelating agent type and concentration along with the pH-effect and ionic strength, and on the other hand, by the heavy metal type and concentration and its speciation state. In some cases, sequential extraction steps might be necessary and even the use of mixtures of different chelating agents.

Based on the knowledge that metals have a high affinity for thiol groups of enzymes and proteins, Schwartz (2008) patented a chelant extraction process for removing heavy metals (such as mercury, lead, uranium, cadmium, etc.) from food by a vacuum soaking process using different types of ligands such as concentrated proteins

471 (legume protein, pulse legume protein, vegetable protein, grain protein, bacterial 472 metalloregulatory protein) and organic acids (phytic acid) and other chelants (EDTA, 
473 BAL, DMSA, DMPS, etc.). The author suggested that another way of incorporating

474 ligands could be by adding them to a coating, sauce, or marinade to be eaten with the 475 fish, thereby avoiding its absorption by the digestive tract.

Mercury is the most studied metal in fish muscle. Cohen and Schrier (1975)

477 carried out a study in carp (Ciprinus carpio) and sheepshead (Archosargus 478 probatocephalus) by using a dilution of $1.2 \mathrm{~g}$ of sodium borohydride (for $1 \mathrm{ppm}$ of 479 mercury in $100 \mathrm{~g}$ of fish protein concentrate) for 20-30 min at room temperature. 480 Spinelli et al. (1973) studied the effectiveness of cysteine in reducing the mercury 481 content of comminuted fish and fish protein concentrate from Pacific halibut (Hippoglossus stenolepis) and hake (M. productus) where it was reported that the amount of mercury extracted was related to the tissue $\mathrm{pH}$ and the concentration of cysteine (0-0.5\%). A similar study was carried out in precooked "yellow tuna" where it 485 was reported that about $66-75 \%$ of mercury was removed from shredded muscle by a two-hour extraction at $5^{\circ} \mathrm{C}$ by washing with dilute hydrochloric acid containing $0.33 \%$ cysteine hydrochloride. The same procedure was used for thick slices but with a 24hour extraction period (Yannai and Saltzman, 1973).

It is important to bear in mind that the amount of mercury extracted was related 490 to the ligand concentration (in order to facilitate effective competition) and the medium $\mathrm{pH}$. In general, it seems that the lower the solution $\mathrm{pH}$, the better the alleviation of mercury from the fish muscle. Mercury removal efficiency by $0.5 \%$ cysteine 493 hydrochloride solution could be about $80 \%$ in tuna slices under the most favourable 494 conditions (pH, stirring, extraction time, muscle:water ratio, etc.), but no higher, due to 495 the difficulty in breaking some strong bonds (Schab et al., 1978). This is in agreement 496 with the findings of Hajeb and Jinap (2009) carried out in minced mackerel 497 (Rastrelliger brachsoma) muscle. These authors reported that mercury reduction 
significantly decreased (up to $81 \%$ ) depending on the $\mathrm{pH}$ of the mixed solution used

499 (citric acid, sodium hydroxide and salt) during the washing treatment. However, Gong et al. (2011) reported no decrease in mercury levels in protein isolates from whitefish

501 (Coregonus clupeaformis) and walleye (Sander vitreus) muscles prepared by $\mathrm{pH}$ 502 shifting in the presence of $5 \mathrm{mM}$ sodium citrate; it only decreased with the addition of $503 \quad 0.5 \%$ cysteine.

504 Regarding the other heavy metals (selenium, cadmium, lead, arsenic), Cohen and Schrier (1975) suggested that they can be reduced in the same manner as mercury. In this respect, Ren et al. (2008) studied the removal of cadmium from scallop hepatopancreas by washing four times with a weak acid solution (2\% acetic acid or

508 citric acid) which produced a reduction in the cadmium level from approx. $39 \mathrm{ppm}$ to $509<0.6$ ppm. Besides using quelants, in a recent study carried out by Topcu and Bulat 510 (2010), it was reported that two strains of Enterococcus faecium showed detoxification

511 properties and could be used in the production of fermented functional foods because of

512 their ability to bind cadmium and lead from the aqueous medium of food (pH 5).

\section{Decontamination of persistent organic pollutants} Persistent organic pollutants (POPs) are bioaccumulated in the fatty fraction of

516 fish and seafood. Therefore, a reduction in the fat content would reduce the content of

517 these undesirable compounds in the raw material. This can be done by simply washing

518 the mince and then decanting the separate fat fraction. These liposoluble compounds

519 can also be removed by oil extraction, using dissolvent oils such as soybean oil, olive 520 oil or fish oil (Baron et al., 2007; Oterhals and Nygård, 2008). As fish oil decontamination does not imply the alteration of nutritionally valuable compounds, it 
can be added as raw material in order to increase the levels of omega -3 fatty acids in

523 foods.

Most of the studies related to removing pollutants have been performed on fishmeal and fish oil using adsorbent treatment with activated carbon (Kawashima et al., 2009; Maes et al., 2010; Oterhals et al., 2007) combined with short-path distillation (Berntssen et al., 2010; Oterhals and Berntssen, 2010), by supercritical $\mathrm{CO}_{2}$ extraction (Kawashima et al., 2009), and deodorization using heat (Maes et al., 2010). process in which the protein content is solubilized in acid or alkaline medium and then precipitated and isolated from the rest of the components. Following this technique, Marmon et al. (2009) obtained more than a 70\% reduction of organic contaminants (dioxins, and polychlorinated biphenyls) in the protein isolate from Baltic herring

534 (Clupea harengus). In this case, most of the pollutants were found in the floating fat emulsion layer after the first centrifugation of the acid and alkaline homogenates. The authors tried to maximize the extraction of fat-soluble contaminants by the addition of solvent (ethanol), oil (olive, fish and soybean), calcium chloride and citric acid.

538 However, the modified acid and alkaline pH-shift method will need further investigation in order to improve its efficiency.

\section{CONCLUSIONS}

The present review has attempted to summarize the great potential that

543 restructured seafood technologies offer in order to elaborate added-value products. In

544 this sense, it is important to remark that, on the one hand, the methodology will clearly

545 depend on raw material properties (mainly protein content and functional qualities)

546 especially when using thermal induced and cold gelation technology. On the other hand, 
547 seafood restructuration offers the opportunity of adding functional components not only

548 to reinforce nutritional and health characteristics, but also to remove unpleasant

549 components, as is the case of fats, colours, contaminants, etc. Moreover, restructured

550 seafood products provide an opening for the creation of new presentations that will

551 widen the range of marketing possibilities, aimed at the new type of consumer who is

552 looking not only for healthy food but for food with a new feel-good factor.

553

554 Acknowledgements

555 The authors would like to thank the Spanish Ministry of Economy and

556 Competitiveness for supporting the project AGL2011-24693 and the Spanish National

557 Research Council (CSIC) for the project 201170E123.

558 


\section{REFERENCES}

Ajinomoto Handbook, Activa ${ }^{\circledR}$ : Ajinomoto Co's Transglutaminase Activa

561

562

563

564

565

566

567

568

569

570

571

572

573

574

575

576

577

578

579

580

581

582

583

Modification of Physical properties of Protein. http://www.ajinomoto.com/

Ashie, I.N.A., and Lanier, T.C. (1999). High pressure effects on gelation of surimi and turkey breast muscle enhanced by microbial transglutaminase. J. Food Sci. 64(4): 704-708.

Baron, C.P., Børresen, T., and Jacobsen, C. (2007). Comparison of methods to reduce dioxin and polychlorinated biphenyls contents in fishmeal: Extraction and enzymatic treatments. J. Agric. Food Chem. 55: 1620-1626.

Beriain, J.M., Gómez, I., Petri, E., Insausti, K., and Sarriés, M. V. (2011). The effects of olive oil emulsified alginate on the physico-chemical, sensory, microbial, and fatty acid profiles of low-salt, inulin-enriched sausages. Meat Sci. 88: 189-197.

Berntssen, M.H.G., Olsvik, P.A., Torstensen, B.E., Julshamn, K., Midtun, T., Goksøyr, A., Johansen, J., Sigholt, T., Joerum, N., Jakobsen, J.V., Lundebye, A.K., and Lock, E.J. (2010). Reducing persistent organic pollutants while maintaining long chain omega-3 fatty acid in farmed Atlantic salmon using decontaminated fish oils for an entire production cycle. Chemosphere. 81: 242-252.

Boles, J.A., and Shand, P.J. (1998). Effect of comminution method and raw binder system in restructured beef. Meat Sci. 49(3): 297-307.

Borderías, J., and Pérez-Mateos, M. (1996). Productos pesqueros restructurados. Alimentaria. 269: 53-62.

Borderías, A. J., Sánchez-Alonso, I., Moreno, P., Dopico, D. C., Tudoran, A., Olsen, S. O., and Careche, M. (2008). Connecting consumer preferences with technical product specifications in wheat dietary fibre enriched seafood restructured products. In: Connecting consumer preferences with technical product specifications in wheat dietary 
584 fibre enriched seafood restructured products, Book of abstracts, pp. 8. Poli, B. M., and 585 Parisi, G., Eds., Firenze University Press 38th annual WEFTA meeting, Firenze, Italy. Borderías, A. J., Sánchez-Alonso, I., and Pérez-Mateos, M. (2005). New applications of fibres in foods: Addition to fishery products. Trends Food Sci. Technol. 16: $458-465$. textural properties of fish heat-induced gels. J. Aquat. Food Prod. Technol. 16: 19-30. fortified with omega 3 fatty acids. Food Sci. Technol. Int. 16: 31-42. dietary fibre and MTGase on the quality of mackerel surimi gels. J. Sci. Food Agric. 89: 1648-1658.

600 Careche, M., Calvo-Dopico, D., and Cañada, J. (2007). Functional food 601 development based on restructured fish and dietary fibre. In: Functional food development based on restructured fish and dietary fibre, Book of abstracts, pp. 20. The fourth open SEAFOODplus conference, Bilbao, Spain.

605 functional seafood products: an international expedition. In: The roadmap to consumer 606 driven functional seafood products: an international expedition, Book of abstracts, pp. 
609 Functional seafood products. In: Functional foods: concept to product, pp. 557-581. 610 Saarela, M., Eds., Woodhead Publishing Limited, Cambridge, UK.

611 Careche, M., Saura-Calixto, F., Díaz-Rubio, M. E., Borderías, J., Sánchez-

612 Alonso, I., Sánchez-González, I., Luten, J. B., Schelvis, R., Schram, E., Kole, A.,

613 Scholten, O. E., Toonen, M. A. J., Carmona, P., Gormley, T. R., Oehlenschläger, J.,

614 Mierke-Klemeyer, S., Elvevoll, E., Nunes, M. L., Bandarra, N., Stoknes, I., and Larsen,

615 E. H. (2008b). Developing functional seafood products. In: Improving seafood products

616 for the consumer, pp. 331-362. Borresen, T., Eds. CRC Press-Woodhead Publishing 617 Limited, Cambridge.

618 Chua, M., Baldwin, T. C., Hocking, T. J., and Chan, K. (2010). Traditional uses 619 and potential health benefits of Amorphophallus konjac K. Koch ex N.E.Br. J. 620 Ethnopharmacology. 128: 268-278.

621 Cohen, G. B., and Schrier, E. E. (1975). Removal of mercury from fish protein 622 concentrate by sodium borohydride reduction. J. Agric. Food Chem. 23: 661-665.

623 CSIC (2006). Borderías, A.J., Carballo, J., and Moreno, H.M. Conformación de 624 Miotomos y mioseptos en productos pesqueros reestructurados. Patent ES 2281 282-A1 625 (16/09/2008) and W0 2007/090916-A1 (16/08/2007).

626 CSIC (2010). Borderías, A. J., Careche, M., and Sánchez Alonso, I. Preparado 627 pesquero reestructurado y procedimiento de elaboración. Fish preparation involves 628 rolling layers of fish to form cylindrical roll, where outer layer has white fish muscle 629 salt, white or coloured fibre, and optionally added ingredient, and inner layer has 630 chopped fish and vegetable fibre. Patent. ES 2 332207-A1. 
632 alimenticio a base de pescado y glucomanano, y procedimiento de obtención. Patent. ES 2363291 (28/07/2011). to Fish Mince. J. Aquat. Food Prod. Technol. 20: 295-307. functional seafood products: Information, acceptability, health and quality perceptions. In: New functional seafood products: Information, acceptability, health and quality perceptions, Book of abstracts, pp. 118. Batista, I., Nunes, M. L., Mendesand R., and

Parisi, G., Eds., National Institute of Biological Resources INRB/IPIMAR, 37th annual WEFTA meeting, Lisboa, Portugal. 180. the Council of 20 December 2006 on nutrition and health claims made on foods. Official Journal of the European Union, L404. amending Regulation (EC) No 1924/2006 of the European Parliament and of the

651 Council with regard to the list of nutrition claims. Official Journal of the European 652 Union, L37. /safereating/chemsafe/additivesbranch/numberlist. 
657 (2011). Mercury distribution and lipid oxidation in fish muscle: Effects of washing and 658 isoelectric protein precipitation. J. Agric. Food Chem. 59: 11050-11057.

660 concentration in fish tissue. Food Additives and Contaminants - Part A Chemistry,

661 Analysis, Control, Exposure and Risk Assessment. 26: 1354-1361.

662

Herranz, B., Tovar, C. A., Solo-de-Zaldívar, B., and Borderías, A. J. (2012a).

Effect of alkalis on konjac glucomannan gels for use as potential gelling agents in

664 restructured seafood products. Food Hydrocoll. 27: 145-153.

665

Herranz, B., Borderías, A. J., Solo-de-Zaldívar, B., Solas, M. T., and Tovar, C.

A. (2012b). Thermostability analyses of glucomannan gels. Concentration influence.

667

668

669

670

671

672

673

674

675

676

677

678

679

680

Food Hydrocoll. 29: 85-92.

Herranz, B., Solo-de-Zaldívar, B., and Borderías, J. A. (2012c). Obtaining a restructured seafood product from non- functional fish muscle by glucomannan addition: first steps. J. Aquat. Food Prod. Technol. (in press). DOI: $10.1080 / 10498850.2011 .632114$

Iglesias-Otero, M. A., Borderías, J., and Tovar, C. A. (2010). Use of konjac glucomannan as additive to reinforce the gels from low quality squid surimi. J. Food Eng. 101: 281-288.

Kawashima, A., Watanabe, S., Iwakiri, R., and Honda, K. (2009). Removal of dioxins and dioxin-like PCBs from fish oil by countercurrent supercritical $\mathrm{CO}_{2}$ extraction and activated carbon treatment. Chemosphere. 75: 788-794.

Kuraishi, C., Sakamoto, J., Yamanazaki, K., Susa, Y., Kuhara, C., and Soeda, C. (1997). Production of restructured meat using microbial transglutaminase without salt or cooking. J. Food Sci. 62(3): 488-490. 
682 Technology, pp. 167-207. Lanier, C.T., and Lee, C.M., Eds., New Cork, Marcel Dekker 683 INC.

684

Lanier, T.C., Carvajal, P., and Yongsawatdigul, J. (2005) Surimi Gelation

685 Chemistry, In: Surimi and Surimi Seafood, pp. 435- 489. Park, J. W., Ed., Taylor and 686 Francis, London.

687 Lee, E. Y., and Park, J. (2002). Pressure inactivation kinetics of microbial 688 transglutaminase from Streptoverticillium mobaraense. J. Food Sci. 67(3): 1103-1107. low-fat, precooked ground beef patties containing carrageenan and sodium alginate. LWT-Food Sci. Technol. 43(9): 1331-1335

692 Maes, J., Vila Ayala, J., De Meulenaer, B., Verhé, R., Gibon, V., and De Greyt, 693 W. (2010). Process optimization for the removal of environmental contaminants from 694 fish oils. OCL - Oleagineux Corps Gras Lipides 17: 81-85. Marmon, S. K., Liljelind, P., and Undeland, I. (2009). Removal of lipids, dioxins, and polychlorinated biphenyls during production of protein isolates from Baltic 697 herring (Clupea harengus) using pH-shift processes. J. Agric. Food Chem. 57: 7819698 7825.

700 behavior and gelling characteristics of myosystem protein gels interacting with 701 hydrocolloids. Food Hydrocolloids. 14(5): 455-461.

702 Moreno, H. M., Carballo, J., and Borderías, A. J. (2008). Influence of alginate 703 and microbial transglutaminase as binding ingredients on restructured fish muscle 704 processed at low temperature. J. Sci. Food Agric. 88: 1529-1536. 
Moreno, H. M., Carballo, J., and Borderías, A. J. (2009a). Study of two different

cold restructuring processes using two different qualities of hake (Merluccius capensis)

muscle with addition of microbial transglutaminase. J. Sci. Food Agric. 89: 1346-1351.

708

Moreno, H. M., Cardoso, C., Solas, M.T. and Borderías, A. J. (2009b).

Improvement of cold and thermally induced gelation of giant squid (Dosidicus gigas)

surimi. J. Aquat. Food Prod.Technol. 18(4): 312-330.

711

Moreno, H. M., Carballo, J., and Borderías, A. J. (2010a). Use of microbial

transglutaminase and sodium alginate in the preparation of restructured fish models

using cold gelation: Effect of frozen storage. Innov. Food Sci. Emerg. Technol. 11: 394400.

Moreno, H. M., Borderías, A. J., and Baron, C. (2010b). Evaluation of some physico-chemical properties of restructured trout and hake during cold gelation and chilled storage. Food Chem. 120: 410-417.

Moreno, H. M., Carballo, J., and Borderías, J. (2010c). Gelation of fish muscle using microbial transglutaminase and the effect of sodium chloride and $\mathrm{pH}$ levels. $J$. Muscle Foods. 21: 433-450.

Moreno, H. M., Carballo, J., and Borderías, A. J. (2011). Application of Response Surface Methodology to study the effect of different calcium sources in restructured fish muscle/alginate system. Ciencia Tecnol. Aliment. 3(1): 209-216. processing. Trends Food Sci. Technol. 9(5): 204-210.

Motoki, M., and Seguro, K. (1998). Transglutaminase and its use for food

Nishinari, K., Williams, P. A., and Phillips, G. O. (1992). Review of the physico-chemical characteristics and properties of konjac mannan. Food Hydrocolloids.

6: $199-222$ 

study on essential oils incorporated into an alginate-based edible coating to assure the safety and quality of fresh-cut Fuji apples. In: Food Industry Journal, pp. 174-188. Leatherhead Food RA.

Oterhals, Å., and Berntssen, M. H. G. (2010). Effects of refining and removal of persistent organic pollutants by short-path distillation on nutritional quality and oxidative stability of fish oil. J. Agric. Food Chem. 58: 12250-12259.

Optimization of activated carbon-based decontamination of fish oil by response surface methodology. Eur. J. Lipid Sci. Technol. 109: 691-705.

Park, J. W. (1995). Surimi gel colors as affected by moisture-content and physical conditions. J. Food Sci. 60: 15-18.

Park, J. W. (1996). Temperature-tolerant fish protein gels using konjac flour. $J$.

Muscle Foods. 7: 165-174.

Park, J. W. (2005). Ingredient technology for surimi and surimi seafood. In:

Surimi and surimi seafood, pp. 649-707. Park, J. W., Eds. CRC Press, Taylor and Francis Group. Incorporation and stabilization of omega-3 fatty acids in surimi made from cod, Gadus morhua. J. Agric. Food Chem., 52: 597-601.

Pérez-Mateos, M., and Montero, P. (2000). Response surface methodology 
acids in fortified surimi seafoods during chilled storage. J. Agric. Food Chem. 52: 79447949.

Pietrowski, B. N., Tahergorabi, R., and Jaczynski, J. (2012). Dynamic rheology

758

759

760

761

762

763

764

765

766

767

768

769

770

771

772

773

774

775

776

777

778

and thermal transitions of surimi seafood enhanced with omega-3-rich oils. Food Hydrocolloids. 27: 384-389.

Pietrowski, B. N., Tahergorabi, R., Matak, K. E., Tou, J. C., and Jaczynski, J. (2011). Chemical properties of surimi seafood nutrified with $\omega-3$ rich oils. Food Chem. 129: 912-919.

Pourang, N., Dennis, J. H., and Ghourchian, H. (2004). Tissue distribution and redistribution of trace elements in shrimp species with the emphasis on the roles of metallothionein. Ecotoxicology. 13: 519-533.

Ramírez, J. A., Uresti, R. M., Velázquez, G., and Vázquez, M. (2011). Food Hydrocolloids as additives to improve the mechanical and functional properties of fish products: A Review. Food Hydrocolloids. 25: 1842- 1852.

Ren, H., Okamoto, Y., Jia, H., Fukuda, R., Kobayashi, A., Goto, S., Endo, H., and Hayashi, T. (2008). Removal of cadmium from scallop processing waste by washing with weak acid solution and utilization of useful constituents for organic fertilizer manufacturing. Fish. Sci. 74: 187-192.

Rourke, T.J., Clarke, A.D., Bailey, M.E., and Hedrick, H.B. (1997). Ionic interactions in algin/calcium/myofibrillar protein gels. J. Muscle Foods. 8(1): 33-46.

Sánchez-Alonso, I., and Ayo, M. (2007). Influence of the addition of conjugated linoleic acid on the technological properties of surimi gels and lipid stability during frozen storage. In: Influence of the addition of conjugated linoleic acid on the technological properties of surimi gels and lipid stability during frozen storage, Book of 
abstracts, pp. 111. National Institute of Biological resources. INRB/IPIMAR,

780 Department of Technological Innovation and Upgrading of fish Products., Eds., 37th annual WEFTA meeting, Lisbon, Portugal. grape antioxidant dietary fibre added to minced fish muscle. Int. J. Food Sci. Technol.

43: 1009-1018.

Sánchez-Alonso, I., Borderías, J., and Careche, M. (2008a). New seafood prototype enriched with coloured dietary fibre. In: New seafood prototype enriched with coloured dietary fibre, Book of abstracts, pp. 53. SEAFOODplus Eds., 5th SEAFOODplus Conference, Copenhaguen.

Sánchez-Alonso, I., Haji-Maleki, R., and Borderías, A. J. (2006). Effect of wheat fibre in frozen stored fish muscular gels. Eur. Food Res. Technol. 223: 571-576.

Sánchez-Alonso, I., Haji-Maleki, R., and Borderías, A. J. (2007a). Wheat fiber as a functional ingredient in restructured fish products. Food Chem. 100: 1037-1043. (2007b). Effect of grape antioxidant dietary fibre on the prevention of lipid oxidation in minced fish: Evaluation by different methodologies. Food Chem. 101: 372-378.

Sánchez-Alonso, I., Jiménez-Escrig, A., Saura-Calixto, F., and Borderías, A. J. (2008b). Antioxidant protection of white grape pomace on restructured fish products during frozen storage. LWT-Food Sci. Technol. 41: 42-50.

Sánchez-Alonso, I., Solas, M. T., and Borderías, A. J. (2007c). Physical study of 800 minced fish muscle with a white-grape by-product added as an ingredient. J. Food Sci. 801 72: E94-E101. 

implications of addition of wheat dietary fibre to giant squid (Dosidicus gigas) surimi gels. J. Food Eng. 81: 404-411. (2009). Raman analysis of surimi gelation by addition of wheat dietary fibre. Food Chem. 112: 162-168.

Saura-Calixto, F. (1998). Antioxidant dietary fiber product: A new concept and a potential food ingredient. J. Agric. Food Chem, 46: 4303-4306. the removal of mercury from fish. J. Sci. Food Agric. 29: 274-280. Schwartz, A. (2008). Systems and methods of removing and managing heavy metals. WIPO Patent Application WO/2008/154452-A1. Motoki, M. (1996). The épsilon-(gamma-glutamyl) lysine in crosslinked casein is an available source of lysine for rats. J. Nutr. 126(10): 2557-2562. seaweed (Eucheuma) powder on the quality of fish cutlet. Int. J. Food Sci. Nutr. 56: 327-335. Reduction of mercury with cysteine in comminuted halibut and hake fish protein concentrate. J. Agric. Food Chem. 21: 264-268. 
828 (2006). Effects of combining microbial transglutaminase and high pressure processing treatments on the mechanical properties of heat-induced gels prepared from arrowtooth flounder (Atheresthes stomias). Food Chem. 94(2): 202-209.

832 Fish and molluscan metallothioneins: A structural and functional comparison. FEBS J. 833 272: 6014-6023. glycemia and other associated risk factors for coronary heart disease in type 2 diabetes A randomized controlled metabolic trial. Diabetes care. 22: 913-919.

Nutr. 85: 1203-1211.

konjac glucomannan on physicochemical properties of myofibrillar protein and surimi gels from grass carp (Ctenopharyngodon idella). Food Chem. 116: 413-418. and freeze-thaw stability of surimi-based shellfish analog products. J. Food Sci. 55: 8791. 